\title{
ANALISIS KERENTANAN SOSIAL EKONOMI RUMAH TANGGA TANI DI KECAMATAN PADANG GELUGUR KABUPATEN PASAMAN
}

\author{
Deri Rahmadani ${ }^{1}$, Yurni Suasti ${ }^{2}$ \\ Program Studi Geografi \\ Fakultas Ilmu Sosial Universitas Negeri Padang \\ Email derirahmadani35@gmail.com
}

\begin{abstract}
Abstrak
Penelitian ini menganalisis kerentanan sosial ekonomi rumah tangga tani di Kecamatan Padang Gelugur Kabupaten Pasaman. Jenis Penelitian ini adalah deskriptif kuantitatif dengan populasi seluruh rumah tangga tani sebanyak 5352 Kepala Keluarga. Penentuan sampel menggunakan teknik proportional random sampling. Hasil penelitian menemukan: (1) tingkat kerentanan sosial rumah tangga tani di empat nagari di Kecamatan Padang Gelugur Kabupaten Pasaman termasuk ketegori agak rentan yaitu Nagari Sitombol Padang Gelugur, Nagari Padang Gelugur, Sontang Cubadak dan Nagari Bahagia Padang Gelugur yang di pengaruhi oleh parameter hukum adat, nilai tradisi, kelembagaan dan pendidikan (2) tingkat kerentanan ekonomi juga termasuk kategori agak rentan yang terdapat di Nagari Padang Gelugur, Nagari Sontang Cubadak dan Nagari Sitombol Padang Gelugur kecuali Nagari Bahagia Padang Gelugur tingkat kerentanan ekonominya kategori rentan.
\end{abstract}

\section{Kata Kunci : Kerentanan Sosial, Kerentanan Ekonomi, Rumah Tangga Tani.}

\section{ABSTRACT}

This study analysed the socio-economic vulnerability of farm households in Padang Gelugur sub-district of Pasaman Regency. The type of this research is quantitative descriptive with the entire farm household population of 5352 households. Determination of sample using technique proportional random sampling. The results of the study found that: (1) the level of social vulnerability of farm households in four villages in Padang Gelugur sub-district, Pasaman regency, including somewhat vulnerable categories, ie Nagari Sitombol Padang Gelugur, Nagari Padang Gelugur, Sontang Cubadak and Nagari Bahagia Padang Gelugur influenced by customary law parameters, the value of tradition, institutional and education (2) the level of economic vulnerability also belongs to a rather vulnerable category found in Nagari Padang Gelugur, Nagari Sontang Cubadak and Nagari Sitombol Padang Gelugur except Nagari Bahagia Padang Gelugur vulnerable level of economic vulnerability. .

Keywords: Social Vulnerability, Economic Vulnerability, Farm Household.

\footnotetext{
${ }^{1}$ Mahasiswa Geografi Fakultas Ilmu Sosial Universitas Negeri Padang

${ }^{2}$ Dosen Geografi Fakultas Ilmu Sosial Universitas Negeri Padang. Pembimbing I: Dra. Yurni Suasti, M.Si
} 


\section{PENDAHULUAN}

Sektor pertanian menjadi sektor andalan di Indonesia dimana sebagian besar pendapatan utama daerah di Indonesia berasal dari sektor pertanian. Kabupaten Pasaman merupakan salah satu kabupaten yang terletak di bagian utara Indonesia yang sebagian besar penduduknya bekerja di sektor pertanian. Berdasarkan data statistik BPS Kabupaten Pasaman tahun 2016, persentase penduduk yang menggantungkan hidupnya disektor pertanian diatas $70 \%$.

Kecamatan Padang Gelugur merupakan salah satu kecamatan yang ada di Kabupaten Pasaman yang mana sektor pertanian merupakan sektor paling dominan sebagai lapangan usaha penduduk di Kecamatan ini yaitu mencapai 59\% dari 23.139 orang penduduk. Hal ini sesuai dengan temuan data statistik Kabupaten Pasaman dimana persentase penduduk yang menggantungkan hidup di sektor pertanian lebih besar dari sektor lainnya.

Berdasarkan data statistik (BPS, 2016) pendapatan perkapita di Kecamatan Padang Gelugur masih tergolong rendah yaitu antara 1 juta - 2 juta rupiah/bulan jika dibandingkan dengan rata-rata pendapatan nasional yaitu Rp. 47,96 juta pertahun atau mendekati 4 juta rupiah/bulan. Data tersebut menunjukan bahwa sektor pertanian merupakan salah satu sektor yang diduga memiliki kerentanan terhadap kehidupan petani baik itu kondisi sosial maupun ekonominya karena kondisi sosial dan ekonomi

merupakan bagian dari aset penghidupan masyarakat.

Menurut (Paimin, dkk : 2010) kerentanan sosial ekonomi ini dapat dilihat dari karakteristik kependudukan tersusun dari parameter: 1) kepadatan geografis, dan 2) kepadatan agraris. Kepadatan geografis adalah jumlah penduduk yang mendiami suatu

wilayah (orang $/ \mathrm{km}^{2}$ ) sedangkan kepadatan agraris adalah jumlah petani yang menggarap lahan per satuan luas (orang petani/ha). Karakteristik sosial lainnya terdiri dari parameter: 3) tingkah laku konservasi masyarakat, 4) hukum adat dalam kegiatan konservasi, dan 5) kearifan atau nilainilai tradisional dalam konservasi. 6) aspek kelembagaan mencakup: keberdayaan lembaga formal dalam konservasi dan keberdayaan lembaga nonformal dalam konservasi tanah yang menunjukkan peran kelembagaan pada kegiatan konservasi. Sedangkan untuk karakteristik ekonominya mencakup parameter: 1) ketergantungan terhadap lahan, dinyatakan dalam persen kontribusi pendapatan usaha tani terhadap 
pendapatan total, 2) tingkat pendapatan, dan 3) kegiatan dasar wilayah (LQ).

Ketergantungan penduduk terhadap lahan merupakan kontribusi pendapatan dari kegiatan pertanian terhadap total pendapatan keluarga. Tingkat pendapatan masyarakat adalah pendapatan keluarga/tahun dan kegiatan dasar wilayah merupakan proporsi jumlah penduduk yang

bekerja di sektor pertanian dibandingkan jumlah penduduk yang bekerja pada seluruh sektor. Tingkat pendapatan masyarakat merupakan rata-rata pendapatan masyarakat. Pendekatan untuk kegiatan dasar wilayah yang digunakan yaitu tenaga kerja sektoral (LQ). LQ menunjukkan dominansi tenaga kerja sektor i pada suatu lokasi dibandingkan dengan dominansi tenaga kerja sektor i pada seluruh wilayah pengamatan. Data ketenagakerjaan dapat diperoleh dari Badan Pusat Statistik (BPS) setempat. Rumus yang dipakai adalah sebagai berikut:

Dimana:

LQ= Koefisien lokasi
Mi = Jumlah tenaga kerja yang bekerja pada sektor i pada satu wilayah pengamatan

M = Jumlah tenaga kerja di satu wilayah pengamatan

$\mathrm{Ri}=$ Jumlah tenaga kerja yang bekerja pada sektor i di seluruh wilayah pengamatan

$\mathrm{R}$ = jumlah tenaga kerja yang ada di seluruh wilayah pengamatan

$\mathrm{R}=\mathrm{R} 1+\mathrm{R} 2+\mathrm{R} 3+\ldots .+\mathrm{Rn}$

Permasalahan ini berfokus pada Kerentanan Sosial Ekonomi Rumah Tangga Tani di Kecamatan Padang Gelugur Kabupaten Pasaman dengan tujuan penelitian ini untuk mengetahui tingkat kerentanan sosial dan tingkat kerentanan ekonomi rumah tangga tani yang ada di Kecamatan Padang Gelugur Kabupaten Pasaman.

\section{METODE PENELITIAN}

Jenis Penelitian yang digunakan adalah deskriptif kuantitatif. Penelitian ini dilaksanakan pada bulan Agustus 2017 di empat nagari di Kecamatan Padang Gelugur Kabupaten Pasaman yaitu Nagari Padang Gelugur, Nagari Bahagia Padang Gelugur, Nagari Sitombol Padang Gelugur, dan Nagari Sontang Cubadak. Peta lokasi penelitian dapat dilihat pada gambar 1 . 


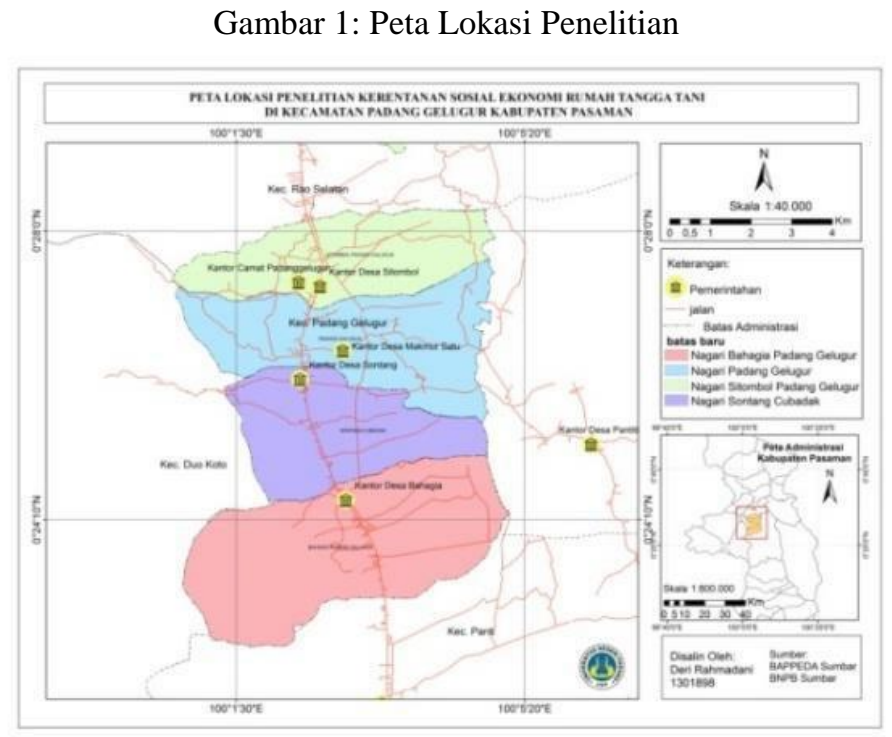

Sumber: Pengelolaan Data Sekunder (2017)

Data yang digunakan dalam yang berkaitan dengan topik penelitian ini berupa data primer yang diperoleh dari pengisian kuesioner dan hasil wawancara mendalam sedangkan penelitian

Analisis kerentanan ini data sekunder di peroleh dari dokumen-dokumen publikasi yang sudah ada dan terkait penelitian. Sumber pustaka lain yang dijadikan data sekunder dalam penelitian ini adalah berupa buku, artikel dari internet, skripsi, thesis, serta makalah dilakukan dengan metode skoring untuk masing-masing indikator/ parameternya. Scoring untuk tiap parameter berbeda-beda dari kategori "rendah" hingga "tinggi". Parameter kerentanan sosial ekonomi ini dapat dilihat pada tabel 1 .

Tabel 1 Formulasi Kerentanan Sosial Ekonomi

\begin{tabular}{|c|c|c|c|c|}
\hline KRITERIA & PARAMETER & BESARAN & KATEGORI & SKOR \\
\hline \multirow{2}{*}{ SOSIAL } & $\begin{array}{l}\text { Kepadatan } \\
\text { Penduduk: } \\
\text { Geografis }\end{array}$ & $\begin{array}{c}<250 \mathrm{jiwa} / \mathrm{km}^{2} \\
250-400 \mathrm{jiwa} / \mathrm{km}^{2} \\
>400 \mathrm{jiwa} / \mathrm{km}^{2}\end{array}$ & $\begin{array}{c}\text { Rendah } \\
\text { Sedang } \\
\text { Tinggi }\end{array}$ & $\begin{array}{l}1 \\
3 \\
5\end{array}$ \\
\hline & $\begin{array}{c}\text { Budaya : } \\
\text { Perilaku/tingkah } \\
\text { laku konservasi }\end{array}$ & $\begin{array}{l}\text { - Masyarakat tahu konservasi, tahu } \\
\text { tekniknya dan melakukan } \\
\text { konservasi } \\
\text { - Masyarakat tahu konservasi tetapi } \\
\text { tidak melakukan } \\
\text { - Masyarakt tidak tahu dan tidak } \\
\text { melakukan konservasi }\end{array}$ & $\begin{array}{l}\text { Rendah } \\
\text { Sedang } \\
\text { Tinggi }\end{array}$ & $\begin{array}{l}1 \\
3 \\
5\end{array}$ \\
\hline
\end{tabular}




\begin{tabular}{|c|c|c|c|c|}
\hline KRITERIA & PARAMETER & BESARAN & KATEGORI & SKOR \\
\hline \multirow[t]{6}{*}{ SOSIAL } & $\begin{array}{c}\text { Budaya } \\
\text { Hukum Adat }\end{array}$ & $\begin{array}{l}\text { - Adat istiadat (Custom) Pelanggar } \\
\text { dikucilkan } \\
\text { - Kebiasaan (folkways) Pelanggar } \\
\text { didenda dengan pesta adat. } \\
\text { - Tata kelakuan (Mores) Pelanggar } \\
\text { biasanya ditegur ketua adat/ orang } \\
\text { lain } \\
\text { - Cara (usage) pelanggar dicemooh } \\
\text { - Tidak ada hukuman }\end{array}$ & $\begin{array}{l}\text { Rendah } \\
\text { Agak Rendah } \\
\text { Sedang } \\
\text { Agak Tinggi } \\
\text { Tinggi }\end{array}$ & $\begin{array}{l}1 \\
2 \\
3\end{array}$ \\
\hline & Nilai Tradisional & $\begin{array}{c}\text { ada } \\
\text { tidak ada }\end{array}$ & $\begin{array}{l}\text { Rendah } \\
\text { Tinggi }\end{array}$ & $\begin{array}{l}1 \\
5\end{array}$ \\
\hline & $\begin{array}{l}\text { Kelembagaan: } \\
\text { Keberdayaan } \\
\text { Lembaga informal }\end{array}$ & $\begin{array}{c}\text { Ada dan berperan } \\
\text { Ada tetapi tidak berperan } \\
\text { Tidak ada }\end{array}$ & $\begin{array}{l}\text { Rendah } \\
\text { Sedang } \\
\text { Tinggi }\end{array}$ & $\begin{array}{l}1 \\
3 \\
5\end{array}$ \\
\hline & $\begin{array}{l}\text { Kelembagaan; } \\
\text { Keberdayaan } \\
\text { lembaga formal }\end{array}$ & $\begin{array}{l}\text { Sangat berperan } \\
\text { Cukup berperan } \\
\text { Tidak berperan }\end{array}$ & $\begin{array}{l}\text { Rendah } \\
\text { Sedang } \\
\text { Tinggi }\end{array}$ & $\begin{array}{l}1 \\
3 \\
5 \\
\end{array}$ \\
\hline & Penduduk yang tamat & $\begin{array}{c}>66 \% \\
33-66 \% \\
<30 \%\end{array}$ & $\begin{array}{l}\text { Rendah } \\
\text { Sedang } \\
\text { Tinggi }\end{array}$ & $\begin{array}{l}1 \\
3 \\
5\end{array}$ \\
\hline & $\begin{array}{c}\text { Kepadatan penduduk } \\
\text { Agraris }\end{array}$ & $\begin{array}{c}<1 \text { orang/ha } \\
1-2 \text { orang/ha } \\
>2 \text { orang/ha }\end{array}$ & $\begin{array}{l}\text { Rendah } \\
\text { Sedang } \\
\text { Tinggi }\end{array}$ & $\begin{array}{l}1 \\
3 \\
5\end{array}$ \\
\hline \multirow{3}{*}{ EKONOMI } & $\begin{array}{c}\text { Ketergantungan } \\
\text { terhadap lahan }\end{array}$ & $\begin{array}{c}<50 \% \\
50-75 \% \\
>75 \%\end{array}$ & $\begin{array}{l}\text { Rendah } \\
\text { Sedang } \\
\text { Tinggi }\end{array}$ & $\begin{array}{l}1 \\
3 \\
5\end{array}$ \\
\hline & Tingkat Pendapatan & $\begin{array}{c}>\text { Rp. } 2.000 .000 \\
\text { Rp 1000.000 - Rp2.000.000 } \\
\text { < Rp 1000.000 }\end{array}$ & $\begin{array}{l}\text { Tinggi } \\
\text { Sedang } \\
\text { Rendah }\end{array}$ & $\begin{array}{l}1 \\
3 \\
5 \\
\end{array}$ \\
\hline & $\begin{array}{c}\text { Kegiatan Dasar } \\
\text { Wilayah } \\
\text { LQ Tenaga Kerja } \\
\text { Sektoral }\end{array}$ & $\begin{array}{l}\mathrm{LQ}<1 \\
\mathrm{LQ}=1 \\
\mathrm{LQ}>1\end{array}$ & $\begin{array}{l}\text { Rendah } \\
\text { Sedang } \\
\text { Tinggi }\end{array}$ & $\begin{array}{l}1 \\
3 \\
5\end{array}$ \\
\hline
\end{tabular}

Sumber: (Paimin et al, 2010 dengan modifikasi penulis)

Formula yang digunakan untuk membuat kelas interval adalah digunakan formula yang dikemukanan oleh Dibiyosaputro (1999) dalam Hermon (2015), yaitu:

$$
\begin{gathered}
\text { dimana : I : besar jarak interval kelas } \\
\mathrm{c}: \text { jumlah skor tertinggi } \\
\mathrm{b}: \text { jumlah skor terendah } \\
\mathrm{k}: \text { Kelas interval kerentanan }
\end{gathered}
$$

$\begin{array}{ccc}\text { Kategori tingkat } & \text { kerentanan } \\ \text { sosial } & \text { ekonomi } & \text { dinyatakan }\end{array}$

berdasarkan hasil perhitungan nilai akhir seluruh parameter, dengan menggunakan klasifikasi peringkat sebagai berikut: Rentan (> 41 ); Agak Rentan (26-41); Sedikit Rentan (<26).

\section{Hasil dan Pembahasan}

1. Tingkat Kerentanan Sosial

Berdasarkan hasil pengolahan

data pada setiap parameter, diketahui bahwa tingkat kerentantan sosial di Kecamatan Padang Gelugur dengan kategori agak rentan (skor kerentanan 16-25) yang terdapat di 4 nagari yaitu 
Nagari Padang Galugua, Nagari kerentanan sosial dapat dilihat pada Bahagia. Klasifikasi tingkat (Tabel 2 dan Gambar 2).

Tabel 2 Klasifikasi Tingkat Kerentanan Sosial

\begin{tabular}{|c|c|c|c|c|c|c|c|c|c|c|c|}
\hline \multirow[t]{2}{*}{ No. } & \multirow[t]{2}{*}{ Nagari } & \multicolumn{7}{|c|}{ Skor } & \multirow{2}{*}{$\begin{array}{l}\text { Skor } \\
\text { Total }\end{array}$} & \multirow{2}{*}{$\begin{array}{l}\text { Skor } \\
\text { Sosial }\end{array}$} & \multirow{2}{*}{$\begin{array}{c}\text { Tingkat } \\
\text { Kerentanan }\end{array}$} \\
\hline & & $\mathbf{P}_{1}$ & $\mathbf{P}_{2}$ & $\mathbf{P}_{3}$ & $\mathbf{P}_{4}$ & $P_{5}$ & $\mathbf{P}_{6}$ & $\mathbf{P}_{7}$ & & & \\
\hline 1. & Padang Galugua & 1 & 1 & 4 & 1 & 3 & 3 & 3 & 16 & $16,33-25,66$ & $\begin{array}{l}\text { Agak } \\
\text { rentan }\end{array}$ \\
\hline 2. & $\begin{array}{ll}\text { Bahagia } & \text { Padang } \\
\text { Galugua } & \\
\end{array}$ & 1 & 1 & 4 & 1 & 3 & 3 & 3 & 16 & $16,33-25,66$ & $\begin{array}{l}\text { Agak } \\
\text { rentan }\end{array}$ \\
\hline 3. & $\begin{array}{ll}\text { Sitombol } & \text { Padang } \\
\text { Galugua } & \\
\end{array}$ & 1 & 1 & 4 & 1 & 3 & 3 & 3 & 16 & $16,33-25,66$ & $\begin{array}{l}\text { Agak } \\
\text { rentan }\end{array}$ \\
\hline 4. & Sontang Cubadak & 3 & 1 & 4 & 1 & 3 & 3 & 3 & 18 & $16,33-25,66$ & $\begin{array}{l}\text { Agak } \\
\text { rentan }\end{array}$ \\
\hline
\end{tabular}

Sumber: Pengolahan Data Primer dan Sekunder (2017)

Keterangan:

$\mathrm{P}_{1}=$ Kepadatan penduduk geografis

$\mathrm{P}_{2}=$ Prilaku/Tingkah laku konservasi

$\mathrm{P}_{3}=$ Budaya Hukum adat

$\mathrm{P}_{4}=$ kearifan lokal/Nilai tradisi

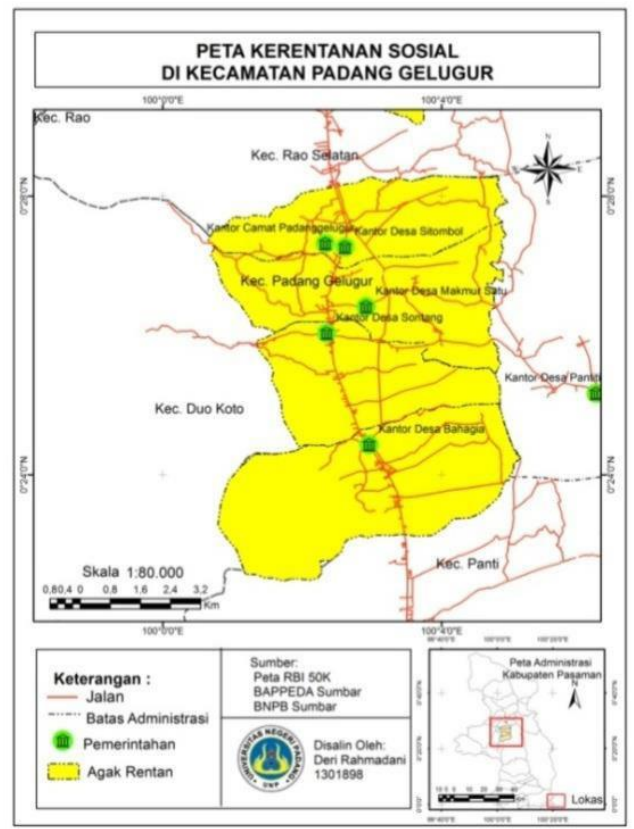

Gambar 2 Peta Sebaran Tingkat Kerentanan Sosial di Kecamaan Padang Gelugur
$\mathrm{P}_{4}=$ kearifan lokal/Nilai tradisi

$\mathrm{P}_{5}=$ Keberdayaan Lembaga informal

$\mathrm{P}_{6}=$ Keberdayaan lembaga formal terhadap konservasi

$\mathrm{P}_{7}=$ Pendidikan

\section{Tingkat kerentanan ekonomi}

Berdasarkan hasil penelitian dan pengolahan data untuk setiap parameter kerentanan ekonomi, diketahui Kecamatan Padang Gelugur didominasi oleh tingkat kerentanan ekonomi kategori agak rentan yang terdapat di nagari yaitu Nagari Padang Gelugur, Nagari Sitombol Padang Gelugur dan Nagari Sontang Cubadak sedangkan untuk Nagari Bahagia Padang Gelugur berada pada tingkat kerentanan ekonomi kategori rentan. Klasifikasi tingkat 
kerentanan ekonomi dapat dilihat pada tabel 3 dan gambar 3.

Tabel 3 Klasifikasi Tingkat Kerentanan Ekonomi

\begin{tabular}{|c|c|c|c|c|c|c|c|c|}
\hline \multirow[b]{2}{*}{ No } & \multirow{2}{*}{ Nagari } & \multicolumn{4}{|c|}{ Skor } & \multirow{2}{*}{$\begin{array}{l}\text { Skor } \\
\text { Total }\end{array}$} & \multirow{2}{*}{$\begin{array}{c}\text { Skor } \\
\text { Kerentanan }\end{array}$} & \multirow[b]{2}{*}{ Tingkat Kerentanan } \\
\hline & & P8 & $\mathbf{P}_{9}$ & $\mathbf{P}_{10}$ & $\mathbf{P}_{11}$ & & & \\
\hline 1. & Padang Galugua & 3 & 3 & 3 & 1 & 10 & $9,33-14,66$ & Agak rentan \\
\hline 2. & Bahagia Padang Galugua & 3 & 5 & 3 & 5 & 16 & $>14,66$ & Rentan \\
\hline 3. & Sitombol Padang Galugua & 5 & 3 & 3 & 3 & 14 & $9,33-14,66$ & Agak Rentan \\
\hline 4. & Sontang Cubadak & 3 & 3 & 3 & 1 & 10 & $9,33-14,66$ & Agak rentan \\
\hline
\end{tabular}

(Sumber: Pengolahan Data Primer dan Sekunder, 2017)

Keterangan:

$\mathrm{P}_{8}=$ Kepadatan penduduk agraris
$\mathrm{P}_{9=}$ Ketegantungan ekonomi terhadap pertanian

$\mathrm{P}_{10}=$ Tingkat pendapatan

$\mathrm{P}_{11}=$ Kegiatan dasar wilayah

Kerentanan sosial di Kecamatan Padang Gelugur ini dipengaruhi oleh parameter budaya hukum adat dengan ketegori agak tinggi dimana budaya hukum adat yang berlaku di masingmasing nagari hanya pada tahap

sindirian/cemooh, parameter lainnya keberdayaan yaitu kelembagaan masyarakat dan pendidikan dengan kategori sedang. Hal ini memberikan pengaruh terhadap perbedaan tingkat kerentanan sosial pada tiap nagari.

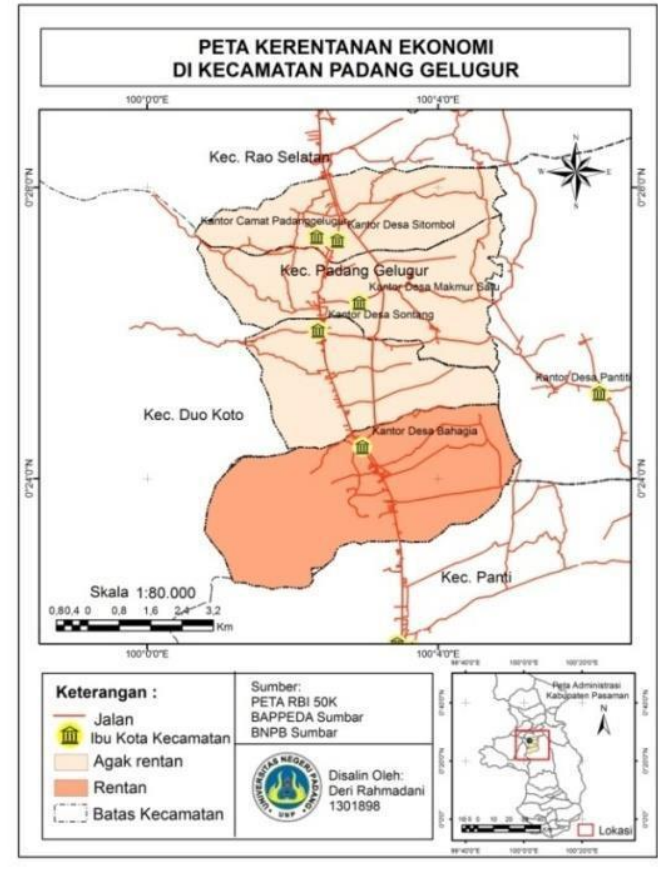

Gambar 3 Peta Sebaran Tingkat Kerentanan Ekonomi di Kecamatan Padang Gelugur 
Hasil analisis kerentanan sosial ekonomi masyarakat di Kecamatan Padang Gelugur yang secara langsung maupun tidak langsung kehidupannya mempengaruhi dan dipengaruhi oleh pertanian menunjukkan bahwa tingkat

Tabel 4 Klasifikasi Ting kerentanan sosial ekonomi kelas kategori agak rentan (skor kerentanan 26 - 41) yang terdapat di 4 nagari yang ada di kecamatan Padang Gelugur seperti terlihat pada (Tabel 3 dan Gambar 5).

\begin{tabular}{|c|l|c|c|c|c|c|}
\hline No Parameter & $\begin{array}{c}\text { Skor } \\
\text { Sosial }\end{array}$ & $\begin{array}{c}\text { Skor } \\
\text { Ekonomi }\end{array}$ & $\begin{array}{c}\text { Skor } \\
\text { Total }\end{array}$ & $\begin{array}{c}\text { Skor } \\
\text { Kerentanan }\end{array}$ & $\begin{array}{c}\text { Tingkat } \\
\text { Kerentanan }\end{array}$ \\
\hline 1. & Padang Galugua & 16 & 10 & 26 & $25,66-40,32$ & Agak rentan \\
\hline 2. & Bahagia Padang Galugua & 16 & 16 & 32 & $25,66-40,32$ & Agak rentan \\
\hline 3. & Sitombol Padang Galugua & 16 & 14 & 30 & $25,66-40,32$ & Agak rentan \\
\hline 4. & Sontang Cubadak & 18 & 10 & 28 & $25,66-40,32$ & Agak rentan \\
\hline
\end{tabular}

(Sumber: Pengolahan Data Primer dan Sekunder, 2017)

Dalam analisis kerentanan, semakin tinggi nilai suatu parameter memberikan gambaran sebuah kondisi yang semakin buruk dari parameter bersangkutan, dan sebaliknya semakain rendah nilai suatu parameternya maka tingkat kerentanannya semakin rendah. Untuk memperoleh sumber penyebab kerentanan dilakukan penelusuran terhadap parameter-parameter yang memiliki nilai tinggi sehingga rekomendasi penanganannya disesuaikan dengan tingkat masalah yang dihadapi.

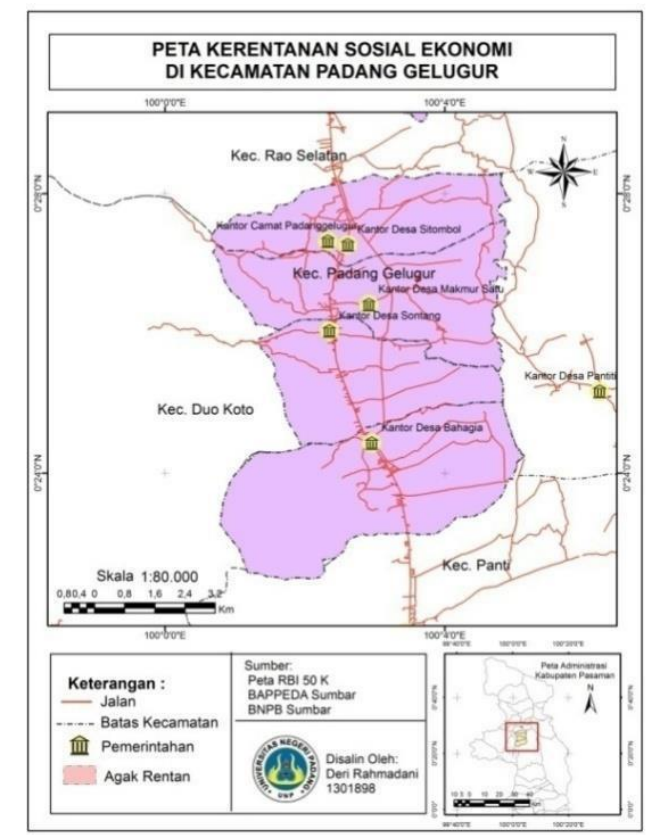

Gambar 4 Peta Sebaran Tingkat Kerentanan Sosial Ekonomi di Kecamatan Padang Gelugur

Kerentanan Sosial Ekonomi Nagari Nagari Padang Gelugur

Hasil analisis terhadap masingmasing parameter penyusun 
kerentanan, Nagari Padang Gelugur merupakan nagari dengan skor kerentanan agak rentan. Secara sosial Padang Gelugur tergolong agak rentan (nilai 16,33-25,66), secara ekonomi tergolong agak rentan (nilai 9,3314,66) dan secara keseluruhan tergolong agak rentan (nilai 20,33$29,66)$. Penyelesaian masalah terhadap kerentanan ini diprioritaskan pada masalah (parameter) dengan skor tinggi yang memberikan pengaruh terhadap peningkatan nilai kerentanan (Gambar 5).

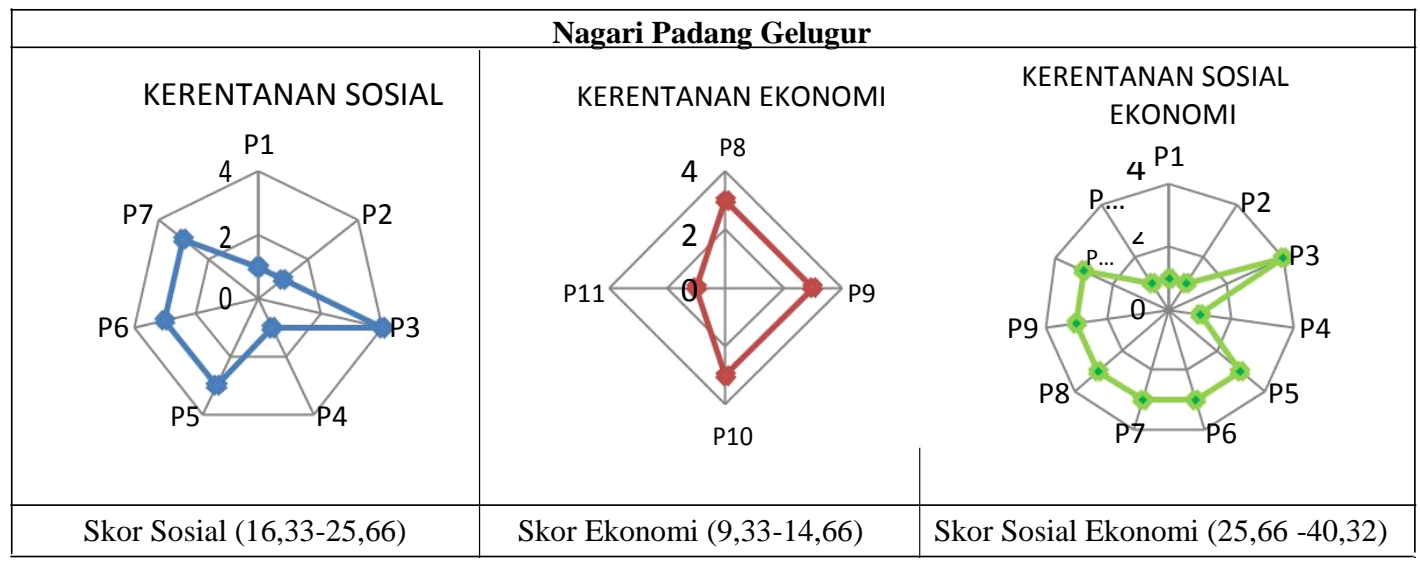

Gambar 5 Karakteristik Parameter Sosial Ekonomi Penyusun Tingkat Kerentanan di Nagari Padang Gelugur (Sumber: Pengolahan Data Primer dan Sekunder 2017, dimodifikasi dari

Keterangan:

$\mathrm{P}_{1}=$ Kepadatan penduduk geografis

$\mathrm{P}_{2}=$ Prilaku/Tingkah laku konservasi

$\mathrm{P}_{3}=$ Hukum adat

$\mathrm{P}_{4}=$ kearifan lokal/Nilai tradisi

$\mathrm{P}_{5} \quad=$ Keberdayaan Lembaga informal terhadap konservasi

Yudi Antomi 2016)

Nilai dari masing-masing parameter yang disimbolkan dalam bentuk titik, menunjukkan semakin mendekati 5 pengaruhnya terhadap tingkat kerentanan akan semakin tinggi, sebaliknya semakin mendekati 0 pengaruhnya terhadap tingkat kerentanan akan semakin rendah.

Kriteria sosial tergolong agak rentan $(16,33-25,66)$ terutama terkait dengan budaya hukum adat yang diberikan pengaruh terhadap peningkatan nilai kerentanan sosialnya. Secara ekonomi kondisi perekonomian masyarakat di Nagari Padang Gelugur tergolong agak rentan (9.33-14,66). Kondisi ini dipengaruhi oleh parameter kepadatan agraris 
dengan kategori sedang $(1,48$ jiwa/Ha), ketergantungan ekonomian masyarakat pada sektor pertanian yang sedang $(50-75 \%)$ serta pendapatan masyarakatnya.

\section{Nagari Bahagia Padang Gelugur}

Hasil analisis kerentanan sosial ekonomi di Nagari Bahagia Padang
Gelugur menunjukkan bahwa secara sosial tergolong agak rentan (nilai 16,33-25,66), secara ekonomi tergolong rentan $(>14,66)$ dan secara keseluruhan tergolong rentan $(>29,66)$ untuk lebih jelas dapat dilihat ada gambar 6.

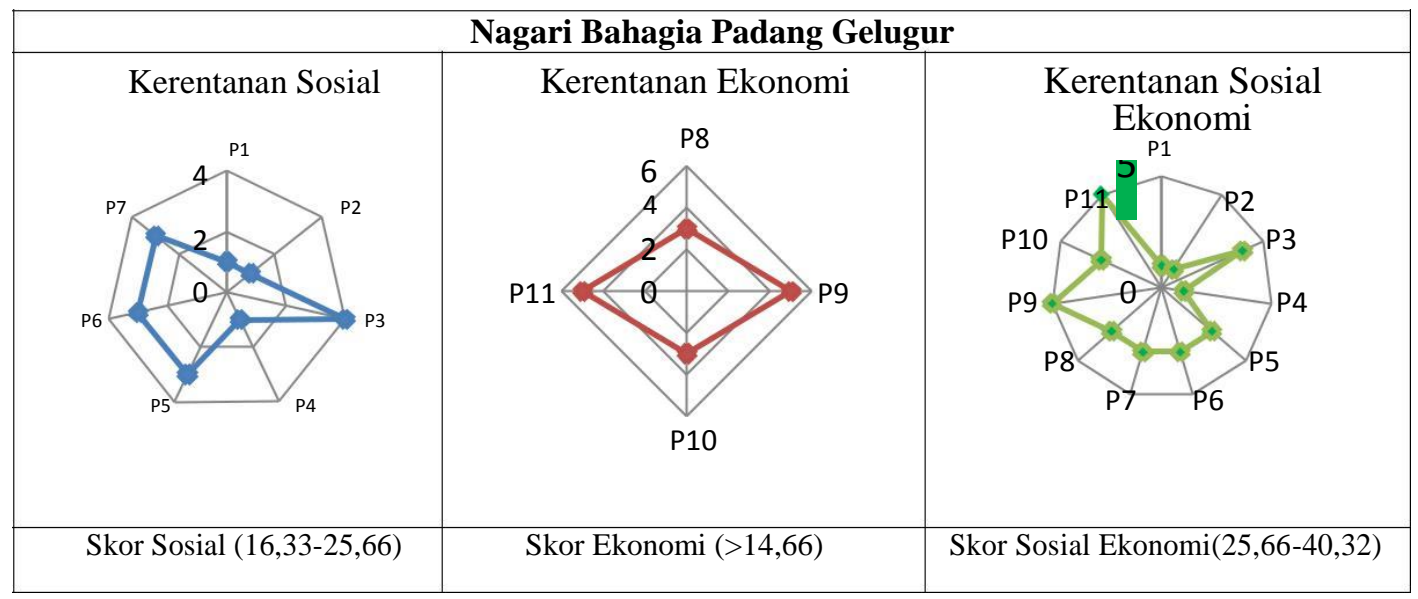

Gambar 6 Karakteristik Parameter Sosial Ekonomi Penyusun Tingkat Kerentanan di Nagari Bahagia Padang Gelugur (Sumber: Pengolahan Data Primer dan Sekunder 2017, dimodifikasi dari Yudi Antomi 2016)

\section{Keterangan:}

$\mathrm{P}_{1}=$ Kepadatan penduduk geografis

$\mathrm{P}_{2}=$ Prilaku/Tingkah laku konservasi

$\mathrm{P}_{3}=$ Hukum adat

$\mathrm{P}_{4}=$ kearifan lokal/Nilai tradisi

$\mathrm{P}_{5} \quad$ = Keberdayaan Lembaga informal terhadap konservasi

\author{
$\mathrm{P}_{6}=$ Keberdayaan lembaga formal terhadap konservasi \\ $\mathrm{P}_{7}=$ Pendidikan Masyarakat \\ $\mathrm{P}_{8}=$ Kepadatan penduduk agraris \\ $\mathrm{P}_{9}=$ Ketegantungan ekonomi terhadap pertanian \\ $\mathrm{P}_{10}=$ Tingkat pendapatan \\ $\mathrm{P}_{11}=$ Kegiatan dasar wilayah
}

Nilai dari masing-masing parameter yang disimbolkan dalam bentuk titik, menunjukkan semakin mendekati 5 pengaruhnya terhadap tingkat kerentanan akan semakin tinggi, sebaliknya semakin mendekati 0 pengaruhnya terhadap tingkat kerentanan akan semakin rendah.

Nilai tersebut merupakan dengan melihat pengaruh masinggambaran masalah sosial ekonomi masing parameter terhadap masyarakat yang dapat ditelusuri peningkatan nilai kerentanan. Kriteria 
sosial tergolong agak rentan (16,3325,66) terutama terkait dengan 3 parameter yang memberikan pengaruh terhadap peningkatan nilai kerentanan yaitu: 1) hukum adat dengan sanksi yang diberikan terhadap pelanggaran lingkungan hanya sebatas cara (usage) dari masyarakat yang pelaku pelanggarannya dicemooh; 2) kearifan lokal/nilai tradisi yang berhubungan dengan konservasi lahan pertanian sudah ditinggalkan masyarakat; dan 3) tidak adanya lembaga informal berperan terhadap konservasi. Secara

ekonomi kondisi perekonomian masyarakat di Nagari Bahagia Padang Gelugur tergolong rentan $(>14,66)$. Kondisi ini dapat dilihat dari parameter ketergantungan ekonomi terhadap pertanian yang tinggi (50-75\%) dan kegiatan dasar wilayah pada sektor pertanian. Pertanian sebagai kegiatan dasar wilayah ditunjukkan dari perhitungan nilai LQ sektor pertanian yang besar dari $1(>1)$.

Nagari Sitombol Padang Gelugur

Hasil analisis kerentanan sosial ekonomi di Nagari Sitombol Padang Gelugur menunjukkan bahwa secara sosial tergolong agak rentan (16,3325,66), secara ekonomi tergolong rentan $(>14,66)$ dan secara sosial ekonomi tergolong rentan $(>29,66)$. Penyusunan prioritas penyelesaian masalah kerentanan sosial ekonomi di Sitomol Padang Gelugur didasarkan kepada parameter-parameter dengan skor tinggi yang memberikan pengaruh terhadap peningkatan nilai kerentanan di Nagari Sitombol Padang Gelugur. (Gambar 7).

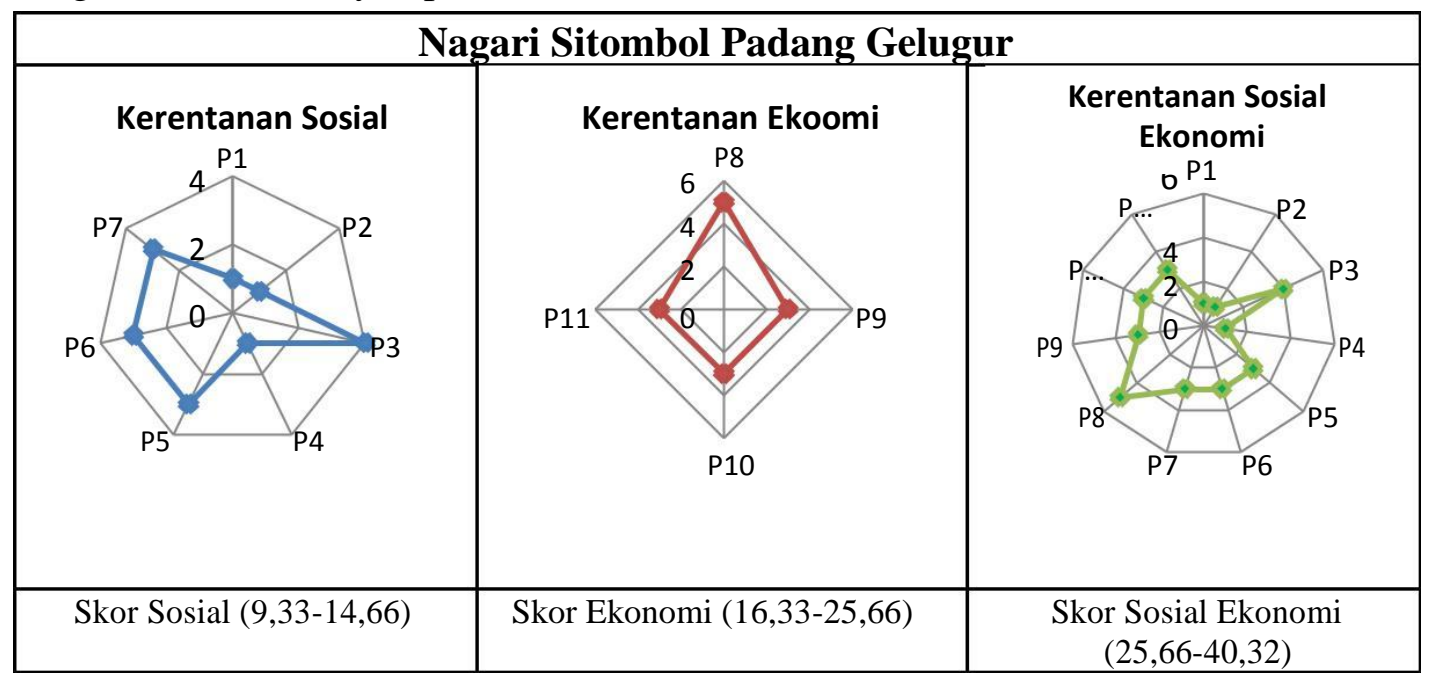

Gambar 7 Karakteristik Parameter Sosial Ekonomi

Penyusun Tingkat Kerentanan di Nagari Sitombol Padang Gelugur

(Sumber: Pengolahan Data Primer dan Sekunder 2017, dimodifikasi dari Yudi Antomi 2016) 
Keterangan:

$\mathrm{P}_{1}=$ Kepadatan penduduk geografis

$\mathrm{P}_{2}=$ Prilaku/Tingkah laku konservasi

$\mathrm{P}_{3}=$ Hukum adat

$\mathrm{P}_{4}=$ kearifan lokal/Nilai tradisi

$\mathrm{P}_{5}=$ Keberdayaan Lembaga informal

$\mathrm{P}_{6}=$ Keberdayaan lembaga formal pada konservasi
$\mathrm{P}_{7}=$ Pendidikan Masyarakat

$\mathrm{P}_{8}=$ Kepadatan penduduk agraris

$\mathrm{P}_{9}=$ Ketegantungan ekonomi terhadap pertanian

$\mathrm{P}_{10}=$ Tingkat pendapatan

$\mathrm{P}_{11}=$ Kegiatan dasar wilayah

Nilai dari masing-masing parameter yang disimbolkan dalam bentuk titik, menunjukkan semakin mendekati 5 pengaruhnya terhadap tingkat kerentanan akan semakin tinggi, sebaliknya semakin mendekati 0 pengaruhnya terhadap tingkat kerentanan akan semakin rendah.

Kriteria sosial tergolong agak rentan $(16,33-25,66)$ terutama terkait dengan 3 parameter yang memberikan pengaruh terhadap peningkatan nilai kerentanan yaitu: 1) hukum adat dengan sanksi yang diberikan terhadap pelanggaran lingkungan hanya sebatas cara (usage) dari masyarakat yang secara spontanitas pelaku pelanggaran dicemooh; 2) kearifan lokal/nilai tradisi yang berhubungan dengan konservasi lahan pertanian sudah ditinggalkan masyarakat; dan 3) tidak adanya lembaga informal berperan terhadap konservasi.

Secara ekonomi kondisi perekonomian masyarakat di Nagari Sitombol Padang Gelugur tergolong rentan $(>14,66)$. Kondisi ini dapat dilihat dari parameter Kondisi ini dipengaruhi oleh parameter kepadatan agraris yang sedang (1,48 jiwa/Ha), dan kegiatan dasar wilayah pada sektor perikanan budidaya. Perikanan budaya sebagai kegiatan dasar wilayah ditunjukkan dari perhitungan nilai LQ sektor pertanian yang besar dari 1 ( > 1).

\section{Nagari Sontang Cubadak}

Hasil analisis terhadap masingmasing parameter penyusun kerentanan, Nagari Padang Gelugur merupakan nagari dengan skor kerentanan agak rentan. Secara sosial Padang Gelugur tergolong agak rentan (16,33-25,66), secara ekonomi tergolong agak rentan $(9,33-14,66)$ dan secara keseluruhan tergolong agak rentan (20,33-29,66). Penyelesaian masalah terhadap kerentanan ini

diprioritaskan pada masalah (parameter) dengan skor tinggi yang memberikan pengaruh terhadap peningkatan nilai kerentanan (Gambar 9). 
Kriteria sosial tergolong agak rentan $(16,33-25,66)$ terutama terkait dengan 3 parameter yang memberikan pengaruh terhadap peningkatan nilai kerentanan yaitu: 1) hukum adat dengan sanksi yang diberikan terhadap pelanggaran lingkungan hanya sebatas cara (usage) dari masyarakat yang secara spontanitas pelaku pelanggaran dicemooh; 2) kearifan lokal/nilai tradisi yang berhubungan dengan konservasi lahan pertanian sudah ditinggalkan masyarakat; dan 3) tidak adanya lembaga informal berperan terhadap konservasi.

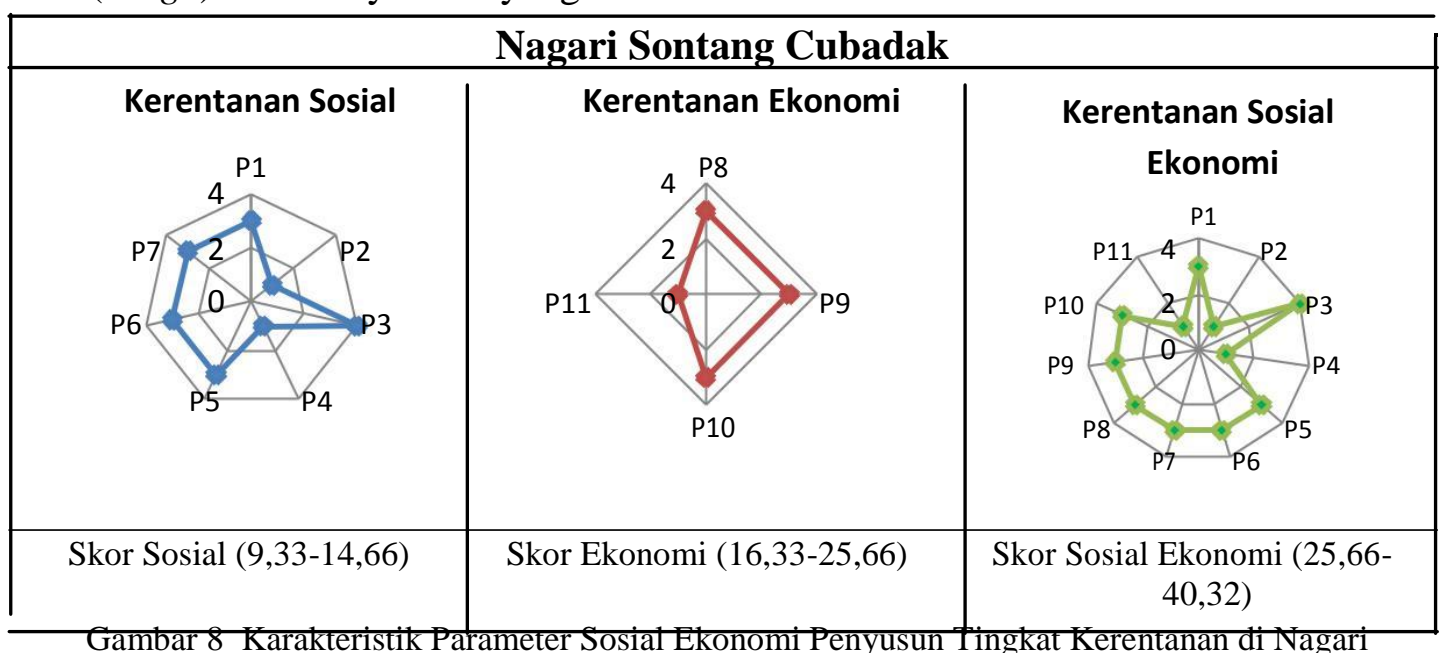

Sontang Cubadak (Sumber: Pengolahan Data Primer dan Sekunder 2017, dimodifikasi dari

Yudi Antomi 2016)

Keterangan:

$$
\begin{aligned}
\mathrm{P}_{1} & =\text { Kepadatan penduduk geografis } \\
\mathrm{P}_{2} & =\text { Prilaku/Tingkah laku konservasi } \\
\mathrm{P}_{3} & =\text { Hukum adat } \\
\mathrm{P}_{4} & =\text { kearifan lokal/Nilai tradisi } \\
\mathrm{P}_{5} & =\text { Keberdayaan Lembaga informal } \\
& \text { terhadap konservasi }
\end{aligned}
$$

Nilai dari masing-masing parameter yang disimbolkan dalam bentuk titik, menunjukkan semakin mendekati 5 pengaruhnya terhadap tingkat kerentanan akan semakin tinggi, sebaliknya semakin mendekati 0 pengaruhnya terhadap tingkat kerentanan akan semakin rendah.

\section{Kesimpulan}

Dari hasil penelitian dan pembahasan yang telah dilakukan pada bab sebelumnya, maka dapat disimpulkan bahwa:
1. Kerentanan sosial yang ada di Kecamatan Padang Gelugur dikategori agak rentan dengan rentang skor (16-25) yang terdapat di 4 nagari yaitu Nagari Padang 
Galugua, Nagari Bahagia Padang Galugua, Nagari Sontang Cubadak, dan Nagari Sitombol Padang Galugua. Kerentanan sosial di Kecamatan Padang Gelugur ini dipengaruhi oleh parameter budaya hukum adat ketegori agak tinggi dan parameter

keberdayaan kelembagaan

masyarakat dan pendidikan dengan kategori sedang. Hal ini memberikan pengaruh terhadap perbedaan tingkat kerentanan sosial yang cukup besar.

2. Tingkat kerentantan ekonomi di KecamatanPadangGelugur didominasi oleh tingkat kerentanan ekonomi kategori agak rentan dengan rentang skor $(9,3-$ 14,6) yang terdapat di Nagari Padang Gelugur, Nagari Sontang Cubadak dan Nagari Sitombol

Padang Gelugur. Sedangkan Nagari Bahagia Padang Gelugur tingkat kerentanan ekonominya kategori rentan dengan skor (> 14). Kerentanan ekonomi ini di pengaruhi oleh semua parameter yang di gunakan dalam analisis kerentana ekonomi ini yaitu kepadatan penduduk agraris, ketergantungan ekonomi terhadap pertanian, tingkat pendapatan dan kegiatan dasar wilayahnya.

\section{DAFTAR PUSTAKA}

Anonim. 2016. Kecamatan Padang Gelugur Dalam Angka 2016. BPS Kabupaten Pasaman.

Anonim. 2016. Kabupaten Pasaman Dalam Angka 2016. Pasaman. BPS Kabupaten Pasaman.

Antomi, Yudi. 2016. Analisis Perubahan Penggunaan Lahan dan Tingkat Kerentanan Sosial Ekonomi untuk Ekosistem Danau Berkelanjutan (Studi Kasus Di

Kawasan Danau Maninjau).

Disertasi. Pascasarjana

Universitas Indonesia Jakarta.

Bintarto R dan Surastopo Hadisumarno. 1981. Metode Analisa Geografi. Jakarta: LP3ES.

Hermon, Dedi. 2015. Geografi Bencana Alam. Jakarta. Rajawali Pres.

Paimin. et. al. (2010). Sidik Cepat Degradasi Sub Daerah Aliran Sungai (SUB DAS). Bogor: Pusat Penelitian dan Pengembangan Konservasi dan Rehabilita. 